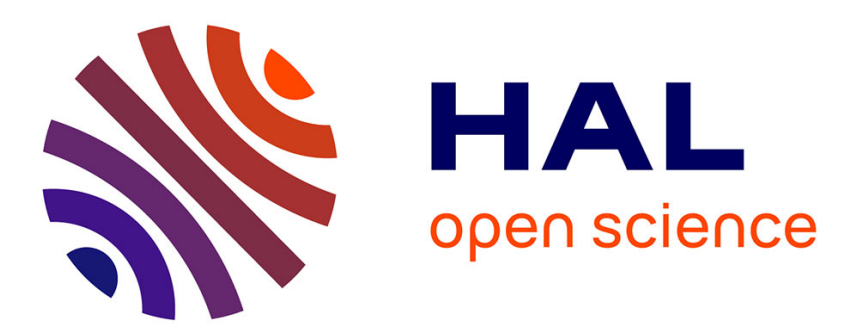

\title{
The super-ACO free electron laser in the UV, first application for time-resolved fluorescence in biology and prospects for soleil
}

\author{
M. Couprie, M. Billardon
}

\section{- To cite this version:}

M. Couprie, M. Billardon. The super-ACO free electron laser in the UV, first application for timeresolved fluorescence in biology and prospects for soleil. Journal de Physique IV Proceedings, 1994, 04 (C9), pp.C9-327-C9-335. 10.1051/jp4:1994956 . jpa-00253518

\section{HAL Id: jpa-00253518 https://hal.science/jpa-00253518}

Submitted on 1 Jan 1994

HAL is a multi-disciplinary open access archive for the deposit and dissemination of scientific research documents, whether they are published or not. The documents may come from teaching and research institutions in France or abroad, or from public or private research centers.
L'archive ouverte pluridisciplinaire HAL, est destinée au dépôt et à la diffusion de documents scientifiques de niveau recherche, publiés ou non, émanant des établissements d'enseignement et de recherche français ou étrangers, des laboratoires publics ou privés. 


\title{
The super-ACO free electron laser in the UV, first application for time-resolved fluorescence in biology and prospects for soleil
}

\author{
M.E. Couprie $*, * *$ and M. Billardon**,*** \\ * CEA DSM DRECAM SPAM, CEN-Saclay, 91191 Gif-sur-Yvette, France \\ ** LURE, Bât. 209D, Université Paris-Sud, 91405 Orsay cedex, France \\ *** ESPCI, 10 rue Vauquelin, 75231 Paris cedex 05, France
}

\begin{abstract}
Storage ring (SR) Free Electron Lasers (FEL) are very promising tunable laser sources in the UV. The Super-ACO UV FEL at $800 \mathrm{MeV}$ was recently improved : enhanced power (roughly two orders of magnitude higher compared to other FELs), 10 hours duration per beam injection, long-term stability, 60 ps FWHM micropulses repeated at $8 \mathrm{MHz}$, generally $\mathrm{CW}$ at the $\mathrm{ms}$ range.This source was first successfully used at $350 \mathrm{~nm}$ : polarized fluorescence decays of the reduced nicotinamide adenine dinucleotide coenzyme in aqueous solution were recorded versus temperature, using the single photon counting technique, leading to accurate measurements and original results, thus demonstrating the quality of the Super-ACO FEL. Moreover, SRFELs appear as unique tools in various scientific fields for two-colours experiments, coupling both the UV FEL and synchrotron radiation, naturally synchronized. Projects are underway on Super-ACO. However, the small gain achieved on the Super-ACO FEL limits its performances such as tunability, short wavelength operation. A FEL implantation on SOLEIL will offer a powerful tunable source between 350 and $100 \mathrm{~nm}$ together with synchrotron radiation. Rather than a single by-pass, an efficient solution with two longer straight sections seems more attractive.
\end{abstract}

\section{INTRODUCTION :}

\subsection{Principle of the Free Electron Laser}

Free Electron Lasers (FEL) are tunable coherent sources resulting from the transverse interaction of a relativistic electron beam with the sinusoidal permanent magnetic field of an undulator (of spatial period $\lambda_{0}$ and peak magnetic field $B_{0}$ ): due to their curved trajectory, the particles then emit synchrotron radiation at the wavelength $\lambda$ and its harmonics: $\quad \lambda=\lambda_{0}\left(1+\mathrm{K}^{2} / 2\right) / 2 \gamma^{2}$

$K$ being the deflection parameter $\left(K=0.94 \mathrm{~B}_{0}(\mathrm{~T}) \lambda_{0}(\mathrm{~cm})\right)$ and $\gamma$ the relative energy of the positron beam. This radiation is stored in an optical cavity in order to interact with the electron bunches at each pass in the undulator field, and the optical pulse can be amplified at the cost of the particler kinetic energy, leading to the laser oscillation. The laser can easily be tuned by modifying the magnetic field of the undulator.

The gain of the system increases with longer wavelengths, lower beam energy, higher electronic density and longer insertion devices.

The spectral width of the laser is mainly determined by the energy of the electron beam, and consequently by the accelerator type. For instance, far infra-red corresponds to Van de Graff accelerators, Infra-red to linear accelerator and the UV is well adapted to storage ring, or to linacs with very short period undulators. As the gain becomes smaller with increasing energy, storage rings are generally preferable to linear accelerators, because of their beam quality. Furthermore, by working at higher energies, the laser power is increased.

The laser temporal structure results from that of the electron beam from which it is generated : macropulses constituted of series of micropulses for RF linacs, micropulses for superconducting linacs and storage rings. 


\subsection{Free Electron Lasers in the UV in operation and projects}

The first operation of a storage ring FEL, demonstrated at Orsay on the ACO storage ring in the visible in 1983 [1]. This was followed by successful experiments on VEPP3 (Russia) in 1988 [2], down to $240 \mathrm{~nm}$, on Super-ACO in 1989 where the dynamics of the laser has been studied in details [3, 4], and in Japan in the visible at TERAS (Tsukuba) in 1991 [5], at NIJI-4 (Tsukuba) in 1993 [6] and at UVSOR (Okazaki) in 1992 [7]. The NIJI-IV experiment is the first dedicated storage ring built for FEL, and, built in collaboration with industry (Kawasaki Heavy Industries). The FEL was also recently realised with a photoinjector, a linear accelerator and a microundulator in Los Alamos at $370 \mathrm{~nm}$ [8].

Various projects are under way, with two dedicated FEL facilities (DELTA [9] and Duke University [10]), as mentionned in table I. The storage ring FEL reached a stage of maturity with the first user experiment recently performed [11], and the operation of dedicated facilities.

Table I : List of Storage Ring Free Electron laser Facilities

\begin{tabular}{|c|c|c|c|c|c|c|c|c|c|}
\hline$\overline{\text { FEL }}$ & Location & Date & $\begin{array}{l}\text { Energy } \\
(\mathrm{MeV})\end{array}$ & $\begin{array}{l}\text { Spectral } \\
\text { Range } \\
(\mathrm{nm})\end{array}$ & $\begin{array}{l}\mathrm{P} \\
\mathrm{mW} / \\
10 \mathrm{~mA}\end{array}$ & $\begin{array}{l}\mathrm{I} \\
(\mathrm{mA} / \\
\text { b. })\end{array}$ & $\tau(h)$ & $\begin{array}{l}\text { Gain } \\
(\%)\end{array}$ & REMARKS \\
\hline $\mathrm{ACO}$ & $\begin{array}{l}\text { Orsay } \\
\text { FRANCE }\end{array}$ & $\begin{array}{l}1978-1987 \\
\text { laser } 1983\end{array}$ & 240 & $650-460$ & 3 & 150 & $1-3$ & 0.2 & $\begin{array}{l}\text { first storage Ring } \\
\text { FEL, characterisation }\end{array}$ \\
\hline VEPP3 & $\begin{array}{l}\text { CEI } \\
\text { Novosibisrk }\end{array}$ & $\begin{array}{l}1978-1994 \\
\text { laser } 1988\end{array}$ & 350 & $\begin{array}{l}690- \\
240\end{array}$ & $\begin{array}{l}3 \\
1\end{array}$ & $\begin{array}{l}20 \\
20\end{array}$ & 0.5 & 10 & $\begin{array}{l}\text { different optical } \\
\text { klystron, linewidth } \\
\text { narrowing, shortest } \lambda\end{array}$ \\
\hline $\begin{array}{l}\text { Super- } \\
\text { ACO }\end{array}$ & $\begin{array}{l}\text { Orsay } \\
\text { FRANCE }\end{array}$ & $\begin{array}{l}1988-? \\
\text { laser } 1989\end{array}$ & $\begin{array}{l}600- \\
600 \\
700 \\
800 \\
\end{array}$ & $\begin{array}{l}690-606 \\
345-355\end{array}$ & $\begin{array}{l}24 \\
10 \\
180 \\
540 \\
\end{array}$ & $\begin{array}{l}45 \\
30 \\
22 \\
25\end{array}$ & $\begin{array}{l}2 \\
5.5 \\
12 \\
\end{array}$ & 2 & $\begin{array}{l}\text { short micropulse } \\
\text { first user experiment }\end{array}$ \\
\hline TERAS & $\begin{array}{l}\text { Tsukuba } \\
\text { JAPAN }\end{array}$ & $\begin{array}{l}1988-1992 \\
\text { laser } 1991\end{array}$ & 230 & 598 & 2.5 & 4 & 1 & $\begin{array}{l}0.02 \\
0.5\end{array}$ & $\begin{array}{l}\text { gain improvement } \\
\text { with a Landau cavity }\end{array}$ \\
\hline UVSOR & $\begin{array}{l}\text { Okazaki } \\
\text { JAPAN }\end{array}$ & $\begin{array}{l}\text { 1988-? } \\
\text { laser } 1992\end{array}$ & 500 & $\begin{array}{l}488 \\
300\end{array}$ & 1 & 10 & 1 & $\begin{array}{l}0.4 \\
0.7\end{array}$ & $\begin{array}{l}\text { gain improvement } \\
\text { with a 2nd RF cavity }\end{array}$ \\
\hline NIJI-4 & $\begin{array}{l}\text { Tsukuba } \\
\text { JAPAN }\end{array}$ & $\begin{array}{l}1990-? \\
\text { laser } 1992\end{array}$ & $\overline{240}$ & 595 & low & & 1 & $5-10$ & $\begin{array}{l}\text { first dedicated SR } \\
\text { FEL, SR built by } \\
\text { Kawasaki H. Ind. }\end{array}$ \\
\hline$\overline{\mathrm{DELTA}}$ & $\begin{array}{l}\text { Dortmund } \\
\text { GERMANY }\end{array}$ & 1989-? & $\begin{array}{l}500- \\
1500\end{array}$ & $\begin{array}{l}\text { Visible } \\
\text { UV }\end{array}$ & & & & $>10$ & $\begin{array}{l}\text { Dedicated facility } \\
\text { 1994: commissioning }\end{array}$ \\
\hline$\overline{\mathrm{DUKE}}$ & $\begin{array}{l}\text { N-Carolina } \\
\text { USA }\end{array}$ & $\begin{array}{l}1989 \text { tranfer } \\
\text { from Stanford }\end{array}$ & 1000 & $\begin{array}{l}\text { visible- } \\
\text { vuV }\end{array}$ & & & & $>10$ & $\begin{array}{l}1994 \text { : commisioning } \\
\text { dedicated facility }\end{array}$ \\
\hline$\overline{\mathrm{KEK}}$ & $\begin{array}{l}\text { Tsukuba } \\
\text { JAPAN }\end{array}$ & 1991 & 750 & 177 & & & & 10 & $\begin{array}{l}\text { 1992: installation of } \\
\text { the optical klystron }\end{array}$ \\
\hline FELI & $\begin{array}{l}\text { Hirakata } \\
\text { JAPAN }\end{array}$ & 1992 & 700 & 200 & & & & & $\begin{array}{l}\text { common installation } \\
\text { with IR LINAC FELs }\end{array}$ \\
\hline NIKHEF & $\begin{array}{l}\text { Amsterdam } \\
\text { NL }\end{array}$ & 1993 & 900 & Vuv & & & & & non dedicated \\
\hline $\begin{array}{l}\text { EUTERP } \\
\text { E }\end{array}$ & $\begin{array}{l}\text { Eindhoven } \\
\text { NL }\end{array}$ & 1993 & 400 & $\overline{X U V}$ & & & & & non dedicated facitity \\
\hline SINBAD & $\begin{array}{l}\text { Daresbury } \\
\text { GB }\end{array}$ & 1993 & 700 & $\overline{X U V}$ & & & & & not yet funded \\
\hline
\end{tabular}

\section{THE UV SUPER-ACO FEL AND PERSPECTIVES}

The Super-ACO FEL characteristics [12] are listed in Table II. The laser power, duration and maximum current of operation are compared with the other storage ring FELs in Table I.

\subsection{Constituting elements}

For FEL experiments in the UV, Super-ACO is now operated with two positron bunches at its nominal energy, $80 \mathrm{O} \mathrm{MeV}$, the highest for the existing FELs, leading to a longer beam lifetime and a good laser stability (see table I). The beam optics is slightly modified in order to reduce the transverse beam sizes at the optical klystron location [3], but the orbit is identical to that of normal synchrotron 
radiation shifts. Some users can now work together with the FEL operation. However, the beam current has an upper limit of $70 \mathrm{~mA}$, because of the presence of quadrupole modes of coherent synchrotron oscillation which modify the electronic density and prevent lasing [13]. FEL shifts are thus compatible with users of the temporal structure of synchrotron radiation, which do not need a high beam current.

Non dedicated storage ring usually have short straight sections, limiting the length of the undulator and thus the gain. Specific devices, called optical klystrons [14], were then proposed and employed, allowing the gain to be increased artificially. They consist of two undulator sections, separated by a large wiggle of magnetic field, created by the so-called dispersive section. In the first undulator occurs the energy modulation of the particules in the bunch, transformed into a density modulation by the dispersive section, leading to a more coherent emission in the second undulator. On Super-ACO, the $3 \mathrm{~m}$ long optical klystron consists of two pure permanent magnets undulators $(10 \times 12.9 \mathrm{~cm}, \mathrm{~K} \max =5.75)$ and a dispersive section of $0.5 \mathrm{~m}$, with independant mechanics for gaps modifications.

The Super-ACO FEL gain is rather small, of the order of $2 \%$. A solution for increasing the gain would be to reduce the bunch length, and thus increase the electronic density, by installing a $500 \mathrm{MHz}$ RF cavity. Such a solution was succesfully adopted on UVSOR [7].

The optical cavity is $18 \mathrm{~m}$ long, or a quarter of the ring circumference, in order to insure the proper synchronization between the bunches stored in the accelerator, and the optical pulses bouncing between the two mirrors. The choice of the mirrors is very critical, because they are exposed to the whole radiation spectrum of the undulator. It can be characterized, not only by its fundamental wavelength (see (1)) where the laser operates, but also by its total output power and its critical wavelength $\lambda \mathrm{c}$, separating the radiation into two equal parts, resp. increasing and decreasing when the beam energy is enhanced. In the case of Super-ACO, $\mathrm{P}=11 \mathrm{~W}$ for $\mathrm{I}=60 \mathrm{~mA}$ and $\lambda \mathrm{c}=70 \AA$.

The rather small gain of the system requires the use of multidielectric mirrors in order to keep cavity losses smaller than the gain. The undulator power obliges us to deposit the layers on sapphire substrates, because of the high thermal conductibility of this material. However, super-polishing is required in order to minimize the scatter losses from the substrates, and especially for shorter wavelengths. This presents an important technological challenge. When the laser is set up at $60 \mathrm{~mA}$, some mirror thermal heating can occur, leading to a local change of its radius of curvature. In that case, a good TEMoo transverse mode may be delivered to users only after a transient time due to thermal loading.

The VUV and X ray radiation emitted in the undulator may also lead a to rapid mirror degradation, depending on the deposition technique. Ion Beam Sputtering, developed for gyrolasers optics, gives more resistant mirrors than the ones produced by simple evaporation technique. In addition, the materials become more absorbant for shorter wavelengths. At $350 \mathrm{~nm}, \mathrm{Ta}_{2} \mathrm{O}_{5} / \mathrm{SiO}_{2}$ mirrors manufactured by Balzers are employed.

Table II : Super-ACO FEL Characteristics

\begin{tabular}{lll}
\hline \hline Storage ring operation & \\
energy range $(\mathrm{MeV})$ & $500-650($ visible $)$ & $600-800(\mathrm{UV})$ \\
lasing duration $(\mathrm{h})$ & $0.8(\mathrm{visible}, 500 \mathrm{MeV})$ & $12(\mathrm{UV}, 800 \mathrm{MeV})$ \\
lasing current range & $60-20 \mathrm{~mA}$ &
\end{tabular}

Spectral features

wavelength

$6300-3500 \AA$,

bandwidth $\quad 1.2 \AA$ at $630 \mathrm{~nm}$

$0.8 \AA$ at $350 \mathrm{~nm}$

Transverse laser modes Dominant mode: TEMon, $\mathrm{n}=0,1,2,3,4,5$
Laser power in the UV at $800 \mathrm{MeV}$
Total extracted power
Available average power
Output peak power
Q-switched output peak power
$0.82 \mathrm{~W}(\mathrm{I}=48 \mathrm{~mA})$
$2 \times 25 \mathrm{~mW}$
$115 \mathrm{~W}$ (RMS micropulse=26 ps)
$0.75 \mathrm{KW}$ (micropulse=20ps)

Temporal structure

microtemporal

macrotemporal

pulses of 60 ps FWHM separated by $120 \mathrm{~ns}$

at the $\mathrm{ms}$ range, either "continuous" or pulsed $(\approx 350 \mathrm{~Hz})$ 


\subsection{FEL characteristics}

\subsubsection{Spectral characteristics}

The spectral range of the FEL is determined by the characteristics of the undulator and by the energy of the accelerator. The Super-ACO FEL covers the visible down to the UV with several sets of mirrors and operates now around $350 \mathrm{~nm}$ with a tunability of $10 \mathrm{~nm}$, a laser bandwidth of the order of 1 $\AA$ at $800 \mathrm{MeV}(\mathrm{K}=5)$. This relatively small tunability is limited by the low gain of the experiment.

The foreseen improvement for spectroscopic applications is to reduce the linewidth with an intracavity etalon.Typical $10^{-5}-10^{-6}$ relative linewidth are possible.

We also plan to operate the laser at shorter wavelegnth between 300 and $250 \mathrm{~nm}$, but with other mirror materials to avoid absorption by the oxyde of tantalum.

In addition, the first odd harmonics can produce a coherent emission, stimulated by the FEL, and could be extracted in our case with a hole coupling in the front mirror of the optical cavity. External harmonic generation with a BBO crystal is planned, in order to produce radiation tunable around $210 \mathrm{~nm}$.

\subsubsection{Laser duration}

Operation at higher beam energies provides longer beam lifetimes and higher laser output powers (see Table I). The Super-ACO FEL at $800 \mathrm{MeV}$ leads to a laser duration of 10 hours, one order of magnitude greater than for the other existing FELs all operating below $500 \mathrm{MeV}$, and this forbids real use of these sources for experimental physics requiring a longer functioning of the sources.

\subsubsection{Laser power}

The laser output power is proportional to the synchrotron radiation power, scaling linearly with the stored current and as the fourth power of the beam energy, and to the extraction efficiency (Brewster window, hole coupling or simply the mirror transmission $\mathrm{T}$ as on the Super-ACO FEL $(\mathrm{T}=0.05 \%)$ ). At $800 \mathrm{MeV}$, the laser power has been enhanced by more than two orders of magnitude in comparison with the other experiments (see Tables I and II).

The available laser output power for the experiment $(25 \mathrm{~mW}$ at $50 \mathrm{~mA})$ with $1 \AA$ bandwidth is four orders of magnitude greater than the band of equivalent synchrotron radiation selected with a monochromator behind a $50 \mathrm{mrad}$ quartz window $(1.3 \mathrm{~mW}$ at $350 \mathrm{~nm}$ in $\Delta \lambda=6 \mathrm{~nm})$.

The power extraction could be improved with more transparent mirrors.

\subsubsection{Polarization}

The FEL is polarized linearly in the horizontal plane, following the horizontal trajectory of the positrons in the vertical field undulator. Other polarizations may then be obtained with a Fresnel rhomb.

\subsubsection{Laser temporal structure}

The temporal structure of the FEL obviously results from that of the bunches stored in the ring (pulses of 300-1000 ps FWHM separated by $120 \mathrm{~ns}$ ). The FEL micropulses are shorter than the synchrotron radiation pulses because the interaction occurs at the maximum of the electron density. The Super-ACO FEL micropulse width has been measured both with a dissector [15], and with a streak camera[16] : at the optimum adjustment, it has a FWHM of 60ps, on the UVSOR FEL it is of the order of 15 ps FWHM, because of shorter electron bunches obtained with the second harmonic RF cavity. Shorter FEL pulses could also be obtained on Super-ACO with a $500 \mathrm{MHz}$ RF cavity.

The rather high repetition rate $(8 \mathrm{MHz})$ is not usual for conventional lasers.

In addition to its microtemporal structure, the FEL can also present a macrotemporal structure at the millisecond range depending on the detuning (longitudinal overlap between the electron bunches and the optical pulses). It is in fact the general situation observed for storage ring FELs, except on SuperACO where it presents a stable regime for perfect synchronism. Great advantage can be taken from this so-called "continuous macrotemporal" structure, especially for the user experiments. It is unique in the Super-ACO FEL and results from the high stability of the storage ring, and probably from the use of positrons.

Q-switch operation can be performed, by an external gain modulation and it leads to a more stable pulse intensity and a peak power increased by a factor of 30 .

\subsubsection{Evolution versus detuning}

The Super-ACO FEL can be obtained on a relative synchronization range of $\Delta f_{R F} / f_{R F}=2-310-6$. Depending on the detuning, one can distinguish five areas of operation, reported in table III. The perfect tuning (type 3) corresponds to the optimum laser parameters (shorter pulse duration and linewidth, higher 
power, $\mathrm{CW}$ operation) but presents some instability (laser micropulse jitter as great as $150 \mathrm{ps}$ and wavelength drift) [17], which are probably not the most desirable for the users. The type 1 and 5 correpond to a stabler laser ( $\mathrm{CW}$, less jitter and intensity flustuations) but with a lower power and larger pulse duration and linewidth. On the contrary, a pulsed temporal structure at the ms range is observed in types 2 and 4), with consequently high intensity fluctuations, and really limits the FEL performances for users.

Table III : stability of the laser parameters versus detuning

\begin{tabular}{|l|l|l|l|l|l|l|l|}
\hline type & $\begin{array}{l}\text { tuning } \\
\text { I } \mathrm{f}_{\mathrm{RF}}(\mathrm{Hz})\end{array}$ & $\begin{array}{l}\text { olaser } \\
(\mathrm{FWHM})\end{array}$ & jitter & macro & power & $\Delta \lambda(\AA)$ & $\lambda$ drift \\
\hline $1-5$ & $>10$ & $70 \mathrm{ps}$ & small & $\mathrm{CW}$ & $<80 \%$ & 0.5 & $<1 \AA$ \\
\hline $2-4$ & $5-10$ & $60-65 \mathrm{ps}$ & $<50 \mathrm{ps}$ & pulsed & $\approx 90 \%$ & $0.3-0.55$ & $2-3 \AA$ \\
\hline 3 & 0 & $60 \mathrm{ps}$ & $<150 \mathrm{ps}$ & $\mathrm{CW}$ & $\max$ & 0.4 & $<1 \AA$ \\
\hline
\end{tabular}

\subsubsection{Stabilization of the FEL}

The perfect synchronisation between the optical pulses and the positrons must be adjusted to within $10^{-8}$. In order to compensate the laser micropulse jitter or drifts in the synchronisation, due to a modification of the optical cavity length induced by thermal changes of the mechanics, a longitudinal feedback on the temporal position of the laser micropulse is developed. The laser micropulse temporal position (measured with the dissector) is compared to a reference position (corresponding to perfect synchronisation), this delay is converted into a voltage, which is applied to the RF pilot to readjust the synchronisation condition with a frequency change. The feedback system has been succesfully tested at 1 $\mathrm{Hz}$, and led to a reduction of the laser micropulse jitter, intensity fluctuations and wavelength drift. The increase of speed of the feedback response is under way, principally by using a higher frequency diagnostic system.

\section{USERS EXPERIMENTS}

\subsection{Time-resolved fluorescence experiments}

\subsubsection{The first user experiment in biology}

Because of the improved characteristics of the Super-ACO UV FEL (stability, power, temporal resolution, polarisation), a first series of experiments using this FEL has been successfully performed to test the feasibility of use of storage ring FELs sources in the UV [11]. Polarized fluorescence decays of the reduced nicotinamide adenine dinucleotide coenzyme (NADH) were studied in aqueous solution, using the single photon counting (SPC) technique. The FEL working point has been first optimized by monitoring the SPC apparatus function. A complete fluorescence experiment required about $30 \mathrm{~min}$ of data acquisition, during which the best integrated instrumental response had a FWHM of 110 ps.

The measurements performed led to the unambiguous separation of two close lifetime components of $0.28 \mathrm{~ns}$ and $0.62 \mathrm{~ns}$ in the fluorescence decays of $\mathrm{NADH}$ at $20^{\circ} \mathrm{C}$, in good agreement with previous works. The thermodynamic parameters obtained from temperature studies show that the NADH fluorescence heterogeneity is consistent with the ground state folding equilibrium of the coenzyme, as characterized by many other spectroscopic techniques. From the fluorescence anisotropy decays, an apparent hydrodynamic radius of about $6 \AA$ is determined, while on the other hand, a large initial depolarization of the fluorescence indicates a fast independent motion of the nicotinamide ring.

The quality of the collected data fully meets the requirements for the study of more complex systems such as fluorescent compounds bound to proteins or membranes. Thus, the feasibility of use of a storage ring UV FEL for this type of time resolved experiments on the subnanosecond time scale has been demonstrated.

\subsubsection{Prospects}

Time-resolved fluorescence techniques could be employed not only in biology, but also for solid state physics where higher intensities are required (for example, studies of a cristal of CsPbCl3 at low temperature, for various laser intensities, detection with a dissector, with A. Rogalev (ESRF) and A. Belski (Moscow State University)). In biology, the study of the enzymatic cofactor at $280 \mathrm{~nm}$ in polarisation for various temperatures and the study of the triptophane at $300 \mathrm{~nm}$ are planned. Anologous experiments could be performed together with the study of the response of the system versus the FEL power. A user hutch has been installed, with a dedicated optical table and with the monitoring of the FEL diagnostics. 


\subsection{Two-color experiments}

The storage ring FEL is really a unique tool for performing two-color experiments, coupling both the laser source and synchrotron radiation, naturally synchronized [18]. Because of the really wide range of synchrotron radiation (SR) and the improved compatibility of the Super-ACO FEL with the other users (see 2.1), one can couple this FEL together with VUV or IR beamlines, and with various SR sources (bending magnets, undulators..) in all scientific domains for various phases of the matter (condensed, surface, gas). Varying the delay between the two sources is very promising. Transport with a fiber optic is underway.

The following applications are under consideration :

- in molecular physics, the photoionisation of $\mathrm{He}+(J$. Lacoursière, M. Meyer, L. Nahon) : SR excites in the $2 \mathrm{p}$ level and FEL photoionizes. First tests were performed concerning the synchronization of the 2 pulses, and position of the beam in SA71.First results were obtained with a mode-locked synchronized Ar laser, in march. Experiment with the FEL planned for sept.94, with a new grating.

-in surfave physics, study of the surface photovoltage effect, in order to study the band modification due to FEL radiation on the photoemission of core level. The FEL would transported by an fiber optic on the undulator beamline SU3 (M. Marsi, A. Taleb, R. Gunther)

- in surface physics, study of the photocarriers induced on HgCdTe by the FEL, with infrared synchrotron radiation from the bending magnet A5 (G. Williams- Brokhaven, P. Dumas)

\section{A FREE ELECTRON LASER ON SOLEIL}

Following the encouraging results obtained on the Super-ACO FEL and taking into account the wide development of storage ring FELs and the potential of two-colour experiments using both FEL and synchrotron radition, a FEL tunable between 3500 and $1000 \AA$ is considered for the new project SOLEIL. Shorter wavelengths could be produced by harmonic generation. A first study viewed the FEL as an option [19], set-up on a by-pass inside the ring, eventhough a significant amount of additional magnetic elements were required and building problems were not solved. A revised project for SOLEIL forsees a storage ring with 12 periods and a reduced its emittance. We now plan to modify this optics, with two longer straight sections for FEL operation : on one of them the undulator will be installed and the second one will be devoted to the injection system... This FEL, coupled with synchrotron radition beamlines, would constitue an original features of the SOLEIL project, in comparison with concurrent machines. Here is described the project on the lengthened ring. The FEL would work under specific conditions of operation of SOLEIL, compatible with the VUV community exploiting the temporal structure of SR.

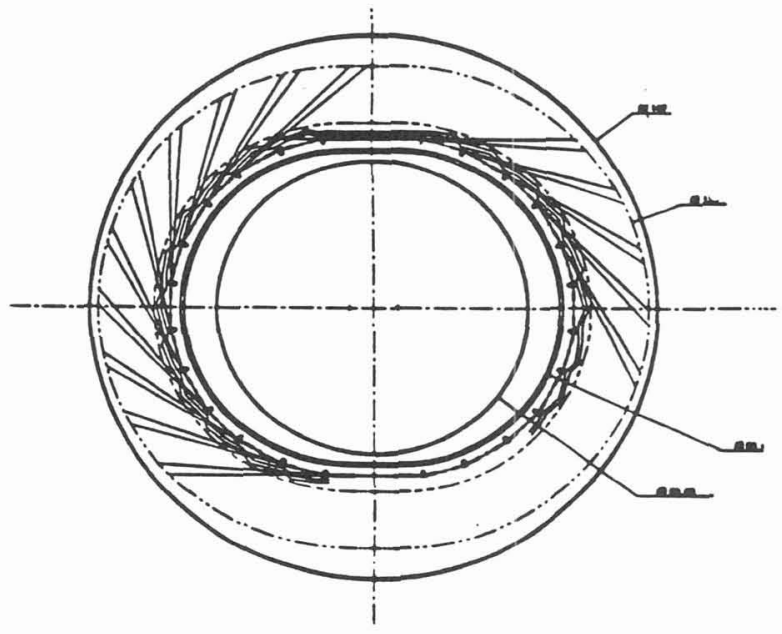

FIG.1 Lay-out of SOLEIL with 12 periods and two longer straight sections 


\subsection{Specific conditions of operation}

The FEL operation requires specific choices for the beam energy, the length of the straight section, the number of stored bunches.

The choice of $E=1.5 \mathrm{GeV}$ results from a compromise between the degradation of the optical elements (undulator radiation power increasing and $X$-ray spectrum widening with $E$ ), the laser output power (increasing with $\mathrm{E}$ ), the gain (diminution with $\mathrm{E}$ ) and the beam lifetime. For gain optimization, the considered beam parameters assume a short pulse length ( 20 ps RMS) but rather large transverse sizes (of the order of 250 microns) in order not to reduce the Touschek lifetime while maintaining short FEL pulses.

A rather long straight section is required to install an undulator for achieving gains of the order of tens of $\%$, and the set-up of magnetic elements for the beam optics needs to be adapted [20]. We plan to make sections of undulators and dispersive sections, with adequated diagnostics and possibly quadrupoles between the sections for the correction of the focusing effect of the insertion devices.

The cavity length should be a sub-multiple of the ring circumference (for insuring the synchronization between the bunches and the light pulses), with the mirror mounts and intra-cavity elements outside the shielding (etalon for linewidth narrowing, Brewster plates for laser and harmonics extraction, acousto-optical modulator for peak laser power extraction..). A system will allow the mirror change from one spectral range to another without breaking the vacuum.

The bunch number should be a multiple of 2 , to insure a stable beam operation, without any coherent synchrotron oscillations, which would prevent correct lasing.

We finally opted for an $39 \mathrm{~m}$ long optical cavity, with four stored bunches and $10.3 \mathrm{~m}$ available on the straight section for the undulator.

\subsection{Laser characteristics}

All these choices leads to the following laser parameters (see table IV).

Table IV : SOLELL FEL parameters

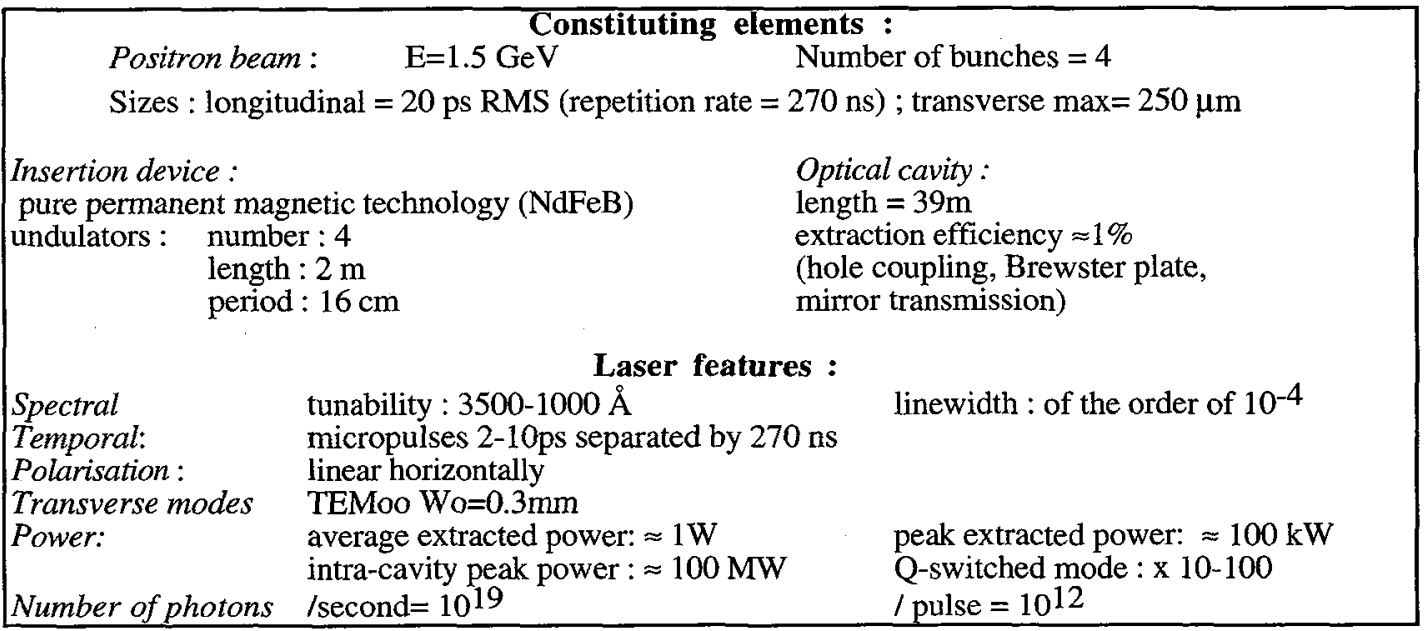

\subsection{Optimization}

The spectral range can be achieved by a simple modification of the magnetic field of the undulator, as illustrated in figure 2 .

The choice of the optical klystron depends on several parameters : the period is chosen in order to raisonably cover the aimed specral range, according to (1).

With undulators sections of $4 \mathrm{~m}$, gains of the order of $50 \%$ are obtained insuring a wider tunability. The various undulator sections could be set-up at different gaps, providing thus two optical klystrons for two different wavelengths with sufficient gain (20\%), leading to a two colors lasers (for instance at 120 and $300 \mathrm{~nm}$ ). Multilayer dielectric mirrors can be optimized for a maximum reflectivity at two different wavelengths. 


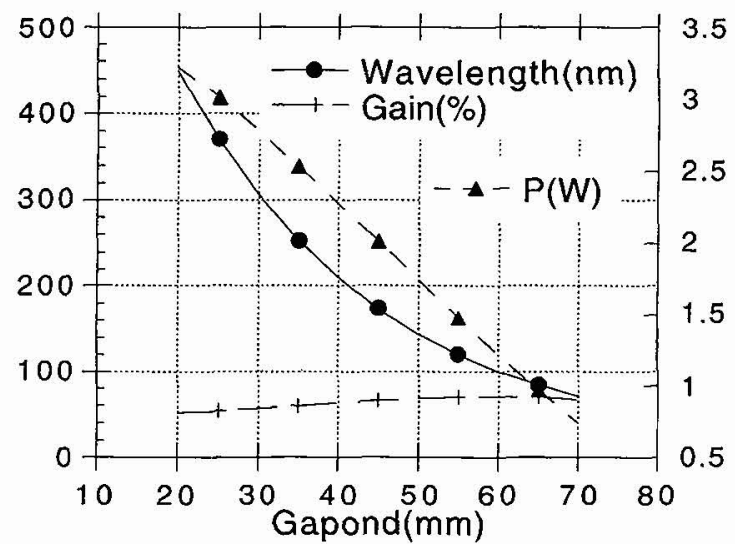

Fig 2: Laser wavelength, avearge power and gain versus the undulator gap. Case of an $8.3 \mathrm{~m}$ long optical klystron, a dispersive section gap of $30 \mathrm{~mm}$ and a laser extraction of $1 \%$.

\subsection{Harmonic generation}

The non linear system constituted by the relativistic bunch circulating in the undulator allows not only gain to be created on the first harmonic, but also coherent harmonic from this same spectrum to be generated. It can be performed with an external laser source, as previously reported in [21], for the production of the 3rd, 5 th and 7 th harmonic of a tripled Nd-Yag laser. It can also be generated from the FEL itself, when the intra-cavity peak power is sufficient. In that case, there are no alignment and synchronization difficulties. In both cases, the extraction of the harmonics, independantly of the excitation wavelengths, remains the major problem (Brewster plate, hole coupling in the front mirror).

For example, with the SOLEIL FEL operating at $1200 \AA, 510^{3}$ coherent photons can be produced at $400 \AA$ (corresponding to a spectral ratio compared to the spontaneous emission from the undulator of $1.210^{3}$ ), in a solid angle of $0.004 \mu \mathrm{rad}$ and a relative bandwidth of $2.810^{-6}$.

\subsection{Lay-out}

The set-up of the SOLEIL FEL is shown on fig. 3. The two laser outputs are installed in dedicated hutches, with diagnostics and user experiments. Besides the experiments taking advantage of the laser temporal structure, power and tunability, two-color experiments, using both synchronized FEL and SR are forseen. For this purpose, there is a SR output from a bending magnet or an undulator in each hutch, with the correct length in order to get both sources properly synchronized, with the FEL slightly in advance in order to be able to adjust the delay between them [22].

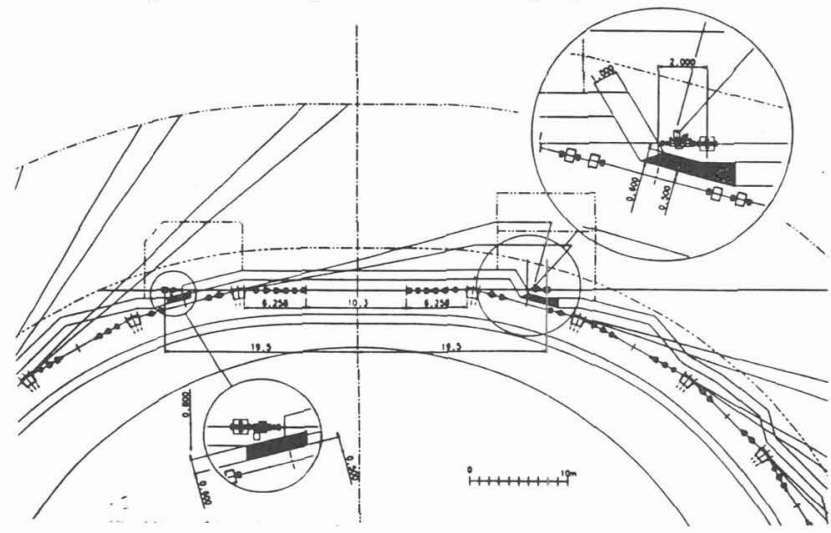

Fig.3 Experimental FEL Lay-out on SOLEIL 


\section{Conclusion}

For one or two years, the Super-ACO FEL will remain unique for carrying out the first user experiments, and demonstrating the potentialitites of two-colors experiments with synchrotron radiation. The FELs on DUKE and DELTA with longer straight sections and dedicated storage ring will then be in operation, leading to a new generation of storage ring FELs. It then appears really essential to develop a new FEL source for future experiments. Let us also note that the frequency of SOLEIL has been chosen in order to be compatible with the CLIO infra-red FEL source, tunable between 2 and 20 microns. The new laboratory will then cover a wide spectral range, from $X$-rays to IR, with various sources (FELs, undulators, wigglers, bending magnets), particularly adapted for the exploitation of the temporal structure of synchrotron radiation. The SOLEIL FEL will be compatible with the VUV community, using a small number of bunches. Finally, it seems unneccessary to build a storage ring just for FEL. A more attractive prospect is the combination of the FEL and VUV work.

\section{REFERENCES}

[1] Billardon M., Elleaume P., Ortega J. M., Bazin C., Bergher M., Velghe M. , Deacon D. A. G. and Petroff Y. Phys. Rev. Lett. 51, 1652 (1983)

[2] Kulipanov G.N., Pinaev I.V., Popik V.M., Skrinsky A.N., Sokolov A.S., Vinokurov N.A., Nucl. Instr. Meth., A296, 1-3 (1990)

[3] Couprie M. E., Velghe M., Prazeres R., Jaroszynski D., Billardon M., Phys. Rev. A . 44, n², $1301-1315$ (1991)

[4] Billardon M., Garzella D., Couprie M. E. Phys. Rev. Lett. 69, n¹6, 2368-2371

[5] Yamada K., Yamazaki T., Sugiyama S., Tomimasu T., Ohgaki H., Noguchi T., Mikado T., Chiwaki M., Susuki R., Nucl. Inst. Meth. A318, 33 (1992)

[6] Yamazaki T., Yamada K., Sugiyama S., Ohgaki H., Sei N., Mikado T., Noguchi T. , Chiwaki M., Suzuki R., Kawai M., Yokoyama M., Owaki K., Hamada S. , Aizawa K., Oku Y. , Iwata A., Yoshiwa M., Nucl. Instr. Meth., A331, 27 (1993)

[7] Takano S., Hama H., Isoyama G., UVSOR activity report 1992, p 4-7

Hama H., Yamazaki J. and Isoyama G. Nucl. Inst. Meth. A 341 (1994) 12-16

[8] O'Shea P.G., Bender S.C., Byrd D.A., Early J.W., Feldman D.W., Fortgang C.M., Goldstein J. C., Newnam B. E., Sheffield R. L., Warren R.W., Zaugg T. J. Nucl. Inst. Meth. A 341 (1994)7-11

[9] "DELTA : a status report" DELTA group University of Dortmund Institute of Physics Aug. 1990

[10] Litvinienko V., Madey J. M. J., Vinokurov N. Proceedings of the Particule Accelerator Conference Washington D. C. may 17-20 (1993)

[11] "First use of the UV Super-ACO Free Electron Laser : time-resolved fluorescence of the coenzyme NADH" Couprie M. E., Tauc P., Merola F., Delboulbé A., Garzella D., Hara T., Billardon M. , in press in Rev. of Scient. Instrum. 65 n 5 (may 1994)

[12] Couprie M. E., Garzella D., Billardon M. Europhysics Lett. 21 (9), 909-914 (1993)

[13] Couprie M. E., Velghe M., Jaroszynski D., Billardon M., Nucl. Inst. Meth. A304 (1991)58-62

[14] Vinokurov N. A., Skrinsky A. M. Preprint INP77.59 Novosibirsk 1977

[15] Couprie M. E., Popik V. M., Zinine E. I., Delboulbé A., Garzella D., Velghe M., Billardon M. Nucl. Inst. Meth. A 318 (1992) 59-64; Couprie M. E., Garzella D., Delboulbé A., Velghe M., Billardon M. Nucl. Inst. Meth. A 331 (1993) 37-41

[16] Couprie M. E., Gontier D., Troussel P., Hara T., Delboulbé A., Billardon M. Rapport d' expérience. CEA/DSM/DRECAM/SPAM -93/377; Hara T., Couprie M. E., Delboulbé A., Troussel P., Gontier D., Billardon M. Nucl. Inst. Meth. A 341 (1994)

[17] Couprie M. E., Litvinenko V., Garzella D., Delboulbé A., Velghe M., Billardon M. Nucl. Inst. Meth. A 331 (1993) 37-41

[18] Nenner I., Morin P., Meyer M., Lacoursière J. and Nahon L. Proceedings of the Maratea Conference, july 1992, to be published in NATO Asi Series; "Free Electron Laser Applications in the $U V^{\prime \prime} 1988$ Technical Digest Series, Vol. 4 (Optical Society of America, Washington DC, 1988)

[19] SOLEIL/S/Rapport/92-03 Couprie M.E. "Une option pour SOLEIL : un laser à électrons libres fonctionnant dans l' ultra-violet installé sur un by-pass intérieur à l' anneau"; Couprie M.E., Ortéga J. M. "Lasers à Electrons Libres" Projet SOLEIL : Argumentation scientifique (Editions de Physique), Editeurs Chandesris D., Morin P. , Nenner I. , juin 1993 p257-262

[20]. CRR SOLEIL/A/94-05 M. Sommer, Longueur d' insertion pour le LEL de SOLEIL

[21] Prazeres R. "Génération d' harmoniques cohérentes dans un klystron optique" Thèse de $\mathrm{l}^{\prime}$ Université de Paris-Sud 9 Mars 1988 ; Prazeres R., Guyot-Sionnnest P., Jaroszynski D., Ortéga J.M., Billardon M., Couprie M. E., Velghe M. and Petroff Y., IEEE april 1991, vol 27 n $^{\circ} 41061-1068$

[22] Lompré L. A., Nenner I. "Lasers et rayonnement synchrotron" Projet SOLEIL : Argumentation scientifique (Editions de Physique), Editeurs Chandesris D., Morin P. , Nenner I., juin 1993 p249-256 